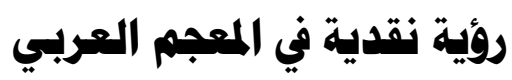

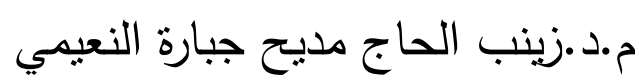

$$
\text { جامعة واسط/كلية الآداب }
$$

خلاصة البحث

يتتاول هذا البحث بالدرس أهم العوائق التي واجهت التأليف المعجمي عند اللغويين والذي بدأ بـه

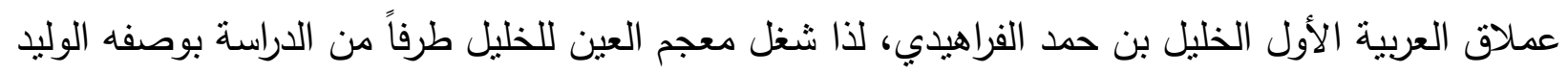

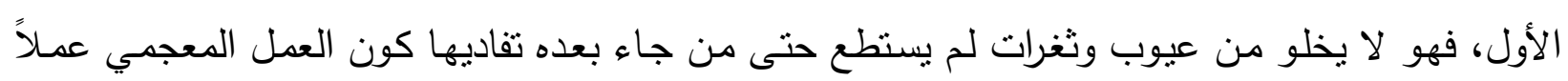

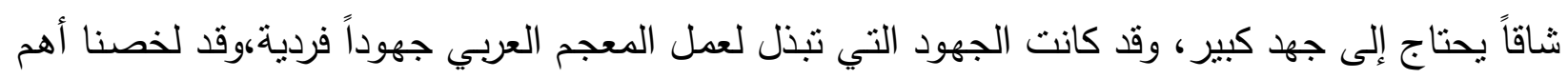

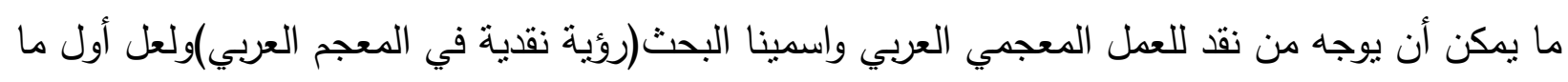

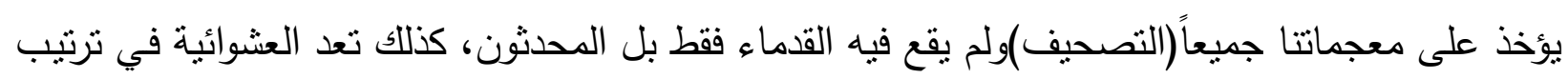

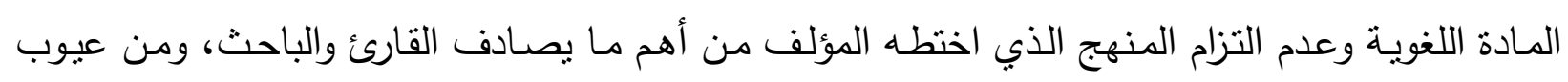

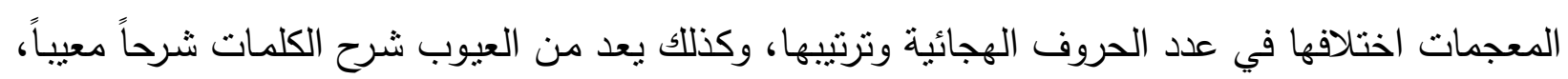

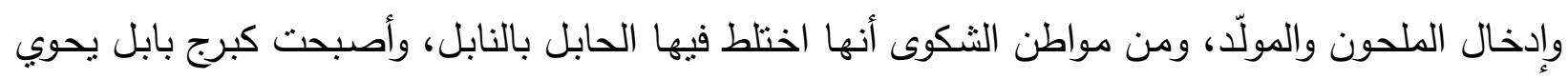

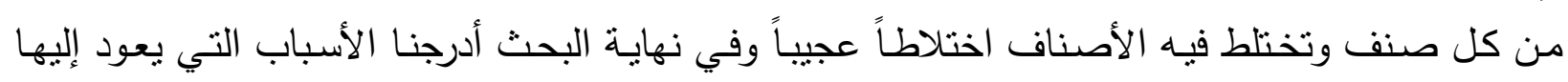
الخلل في المعجم في العصر الديث ودعونا إلى تطوير الصناعة المعجمية واستعمال التقنيات في ذلك.

\section{رؤية نقدية في المعجم العربي في العبي}

عرفت العربية في تاريخها الطويل جهوداً كثيرة، اجتمت على التعائ رصدها وتسجيلها ودرسها وتألفت

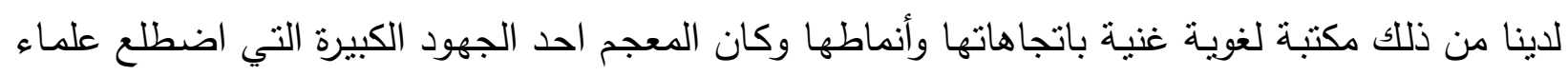

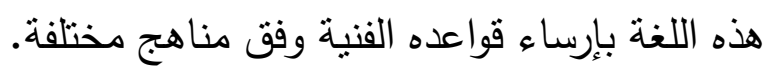

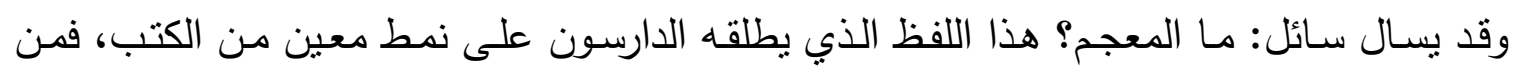

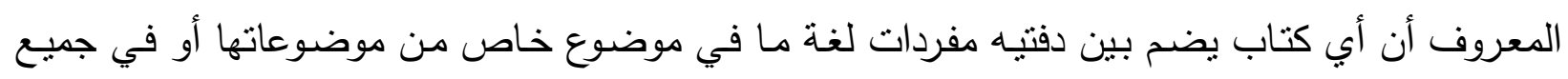

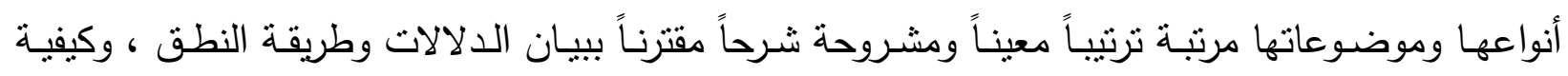

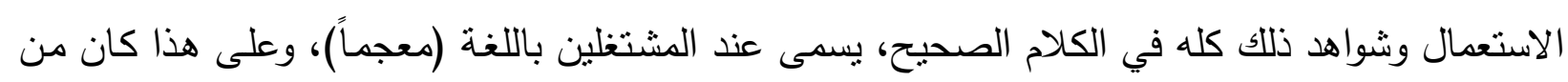

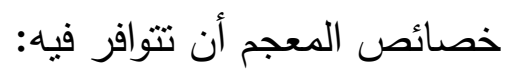

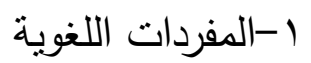

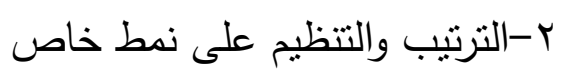

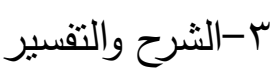
ع -سرد الأمتلة والثواهد، وإلاً لم يصح تسمية الكتاب بهذا الدصطلح، فهل كان إطلاقه مصاحباً لأول معجم

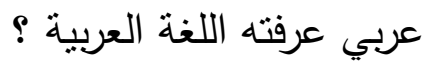


لقد أُطلق مصطلح ( المعجم ) لأول مرة على الكتب التي ألفها رجال الحديث في شيوخهم ورواة

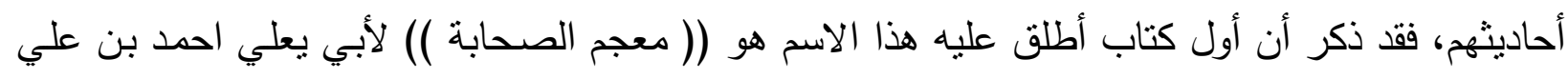

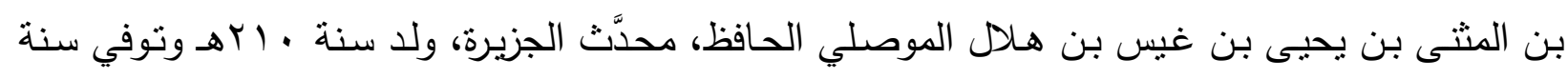

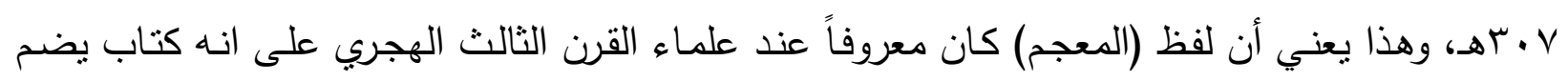

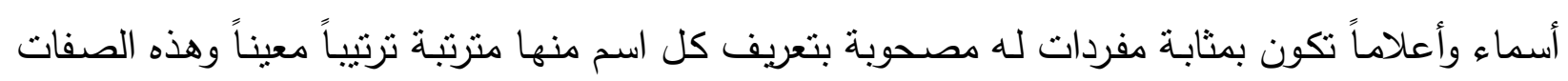

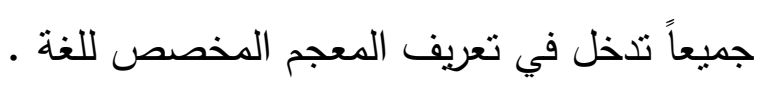
ولم يكن هناك كتاب معجمي في اللغة سمي بهذا الاسم إلا كتاب ( معجم مقاييس اللغة ) لأحمد بن فارس لـاس

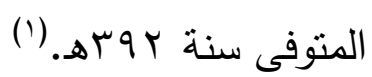
ويمكنتا أن نقول: إن ظهور المعجم العربي في مضمار الدراسات اللغوية العربية كان يعني الاتجاه إلى الحفظ الواعي للغة وحمايتها من الضياع والاختلاط.

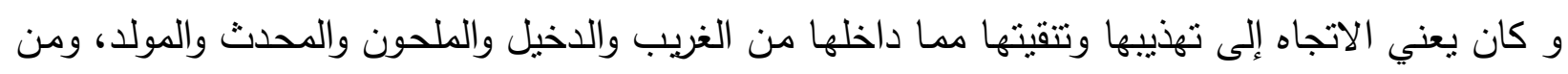

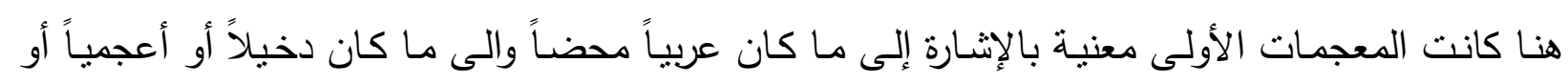

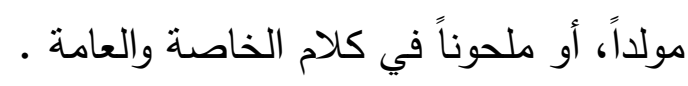

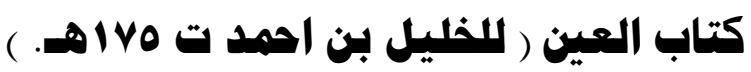

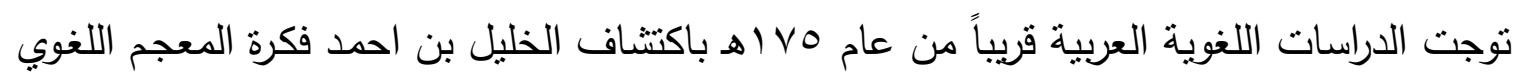
ومحاولته تحقيقها، فقد كان هذا العالم ذا ذهن رياضي مبتكر اعمله في جميع فروع العلم التي اشتغل بهات التها،

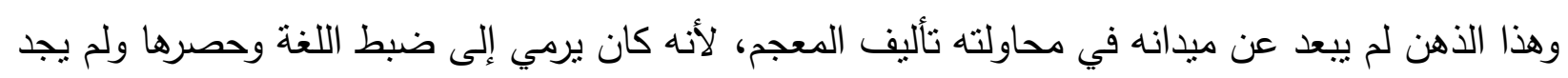

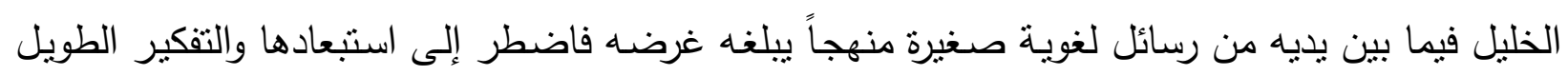

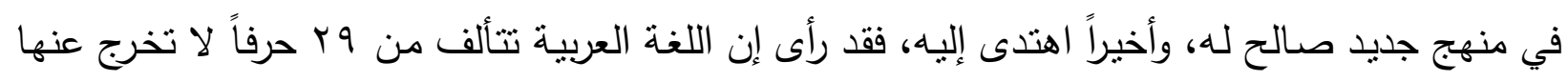

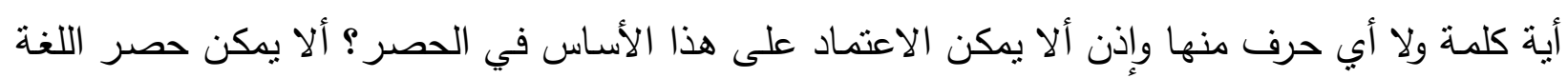
بترتيب هذه الحروف في نظام ثابت ثم استقصاء الكلمات العربية التي يكون الحرف الأول من هذا التهن الترتيب

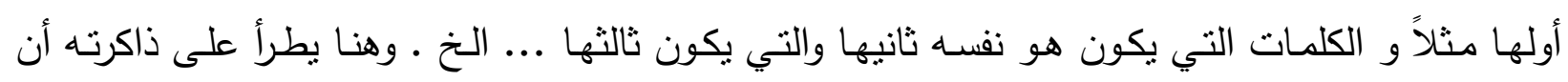

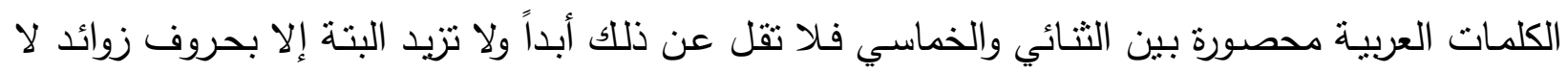
دخل لها في المعنى الأصيل للكلمة المجردة وبهذا المنهج اسنطاع الخليل أن يحصر ألفاظ اللغة العربية

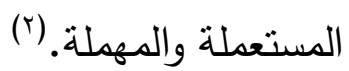

\section{رؤية في هعجم العين}

لما كان كتاب العين أول معجم عربي فمن الطبيعي أَلَّا تخلو الأمور المبتكرة من مآخذ ونقص، لا يحس بها أصحابها لانشغالهم بهذا الوليد الجديد وتصويره على غير مثال سابق. ولا بد من أن أن يكون قاصراً

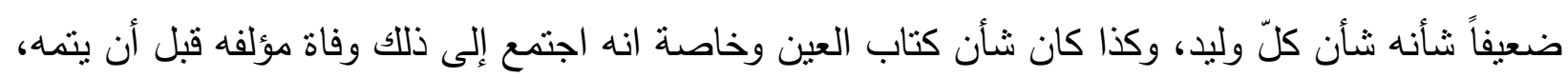

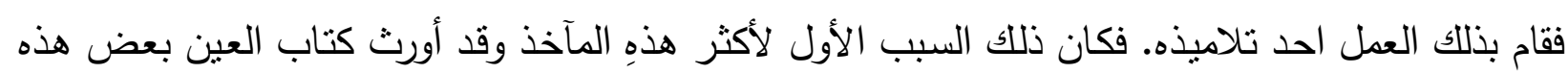


المآخذ المعجمات العربية كلها وبعضها الآخر مدرسته التي أخلصت لمنهجه، وهذا وصف لما أخذه العلماء على كتاب العين خاصة:

1- أول هذه المآخذ - التصحيف - الذي اتهمه بـه أكثر الباحثين بل كلهم وعلله الدكتور احمد أمين في

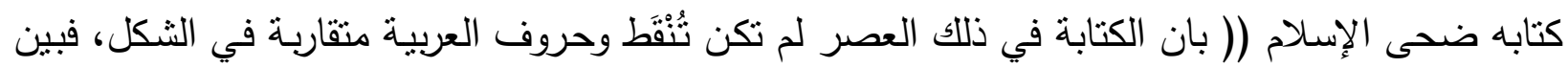

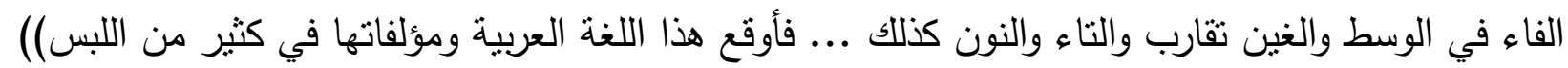
(r) وقد أورد السيوطي في كتابه المزهر ما اخذ على كتاب العين من التصحيف فالسيوطي يقول في مزهره:

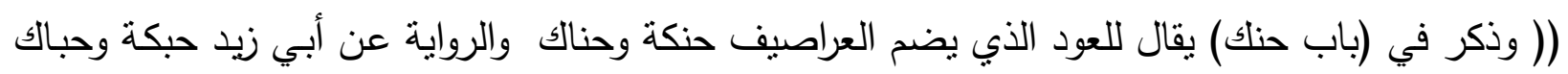

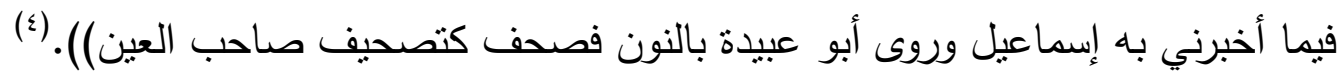

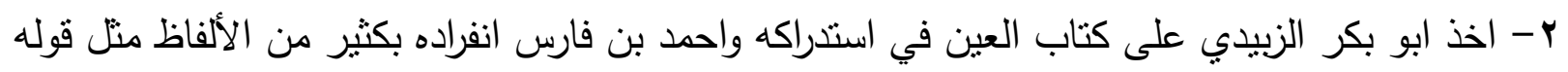

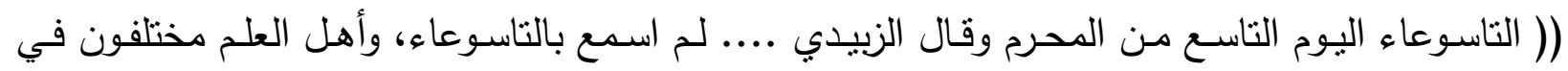

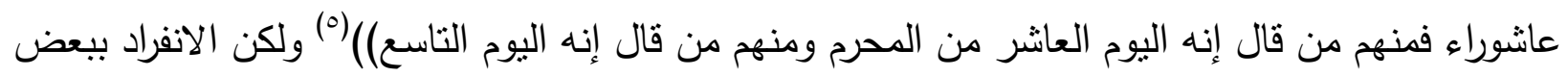
الأثشياء أمر طبيعي وقد انفرد كثثر من اللغوبين بأثنياء مختلفة.

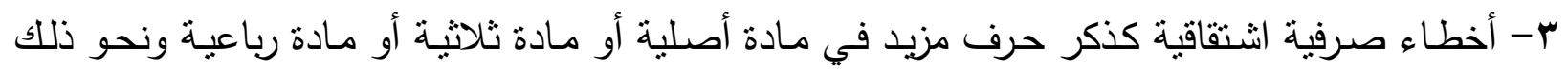

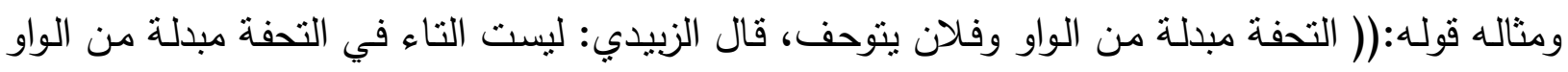

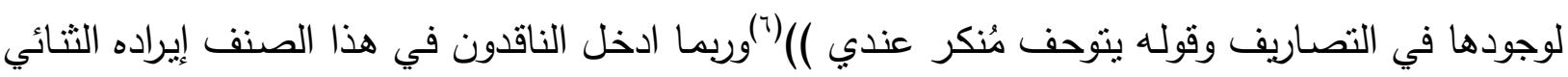

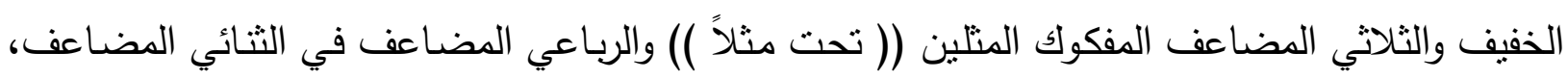

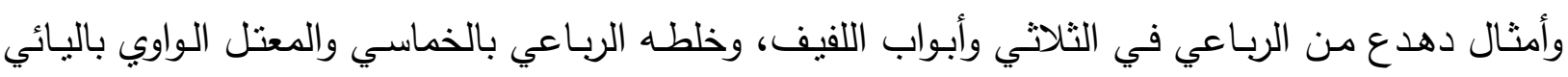

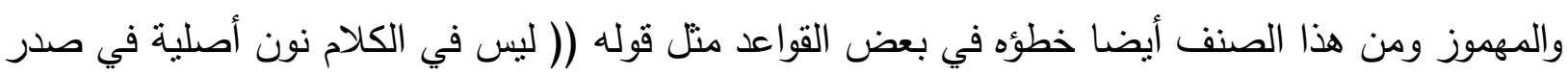

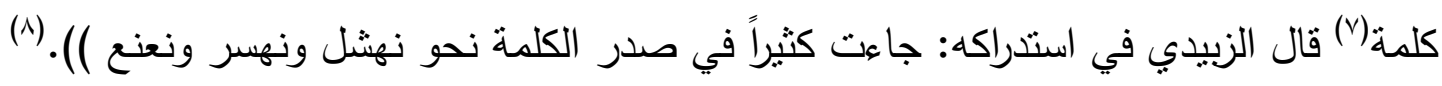

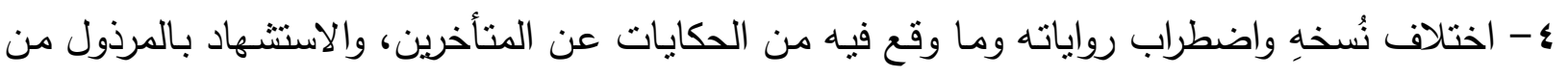

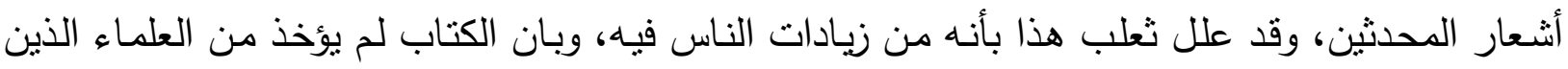

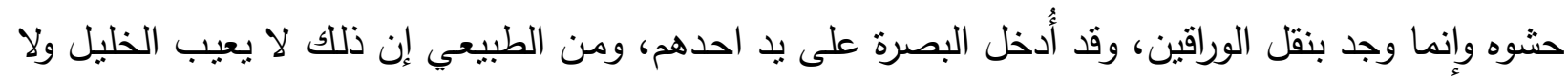

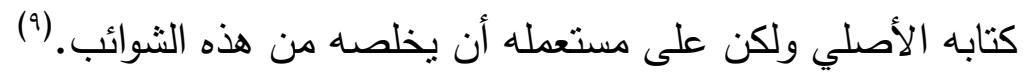

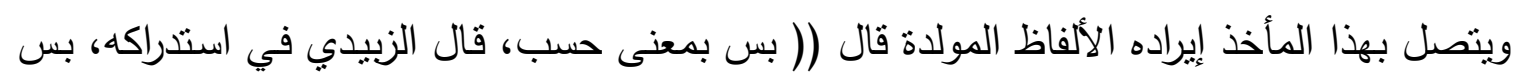

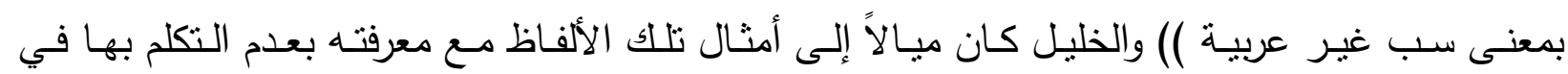
البوادي(·) (1) ه- إهماله أبنية مستعملة في اللغة لم يذكرها لأنه لم بسمع فيها شيئاً، ووصفها بأنها مهملة، وقد استخرك

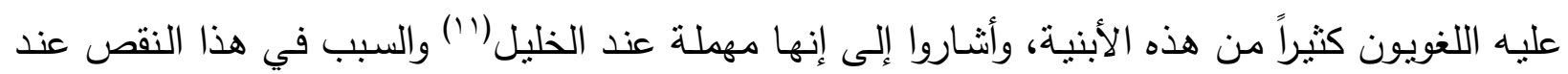
الخليل معروف فهو أول من جمع في اللغة كتاباً كبيراً، فالعلم لا يزال بادئاً في عهده، وقد أكمل من جاء الاء التهاء

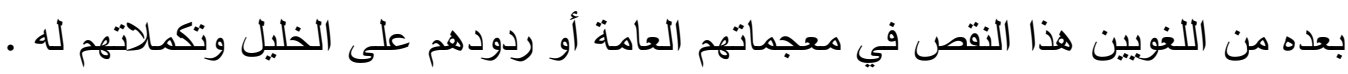


؟- يتصل بالنقص السابق نقص آخر داخل المواد نفسها التي ذكرها ووصفها بأنها مستعملة، فهذه المواد لم يستوف صيغها ولا معانيها المختلفة الكثيرة، وقد أحاطت بهذا النقص الظروف نفسها التي أحاطت بسابقه

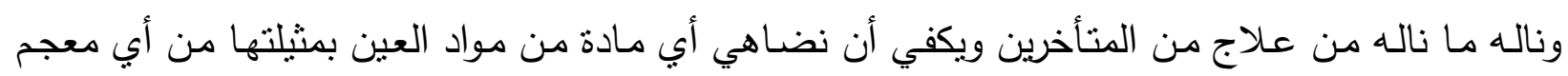

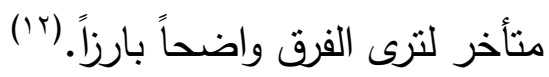

\section{عيوب المعبم العربي}

انتتر التعليم في العصر الحديث انتشاراً فسيحاً، لم يعرف له مثيل في العصور القديمة، واحتاج إلى لى

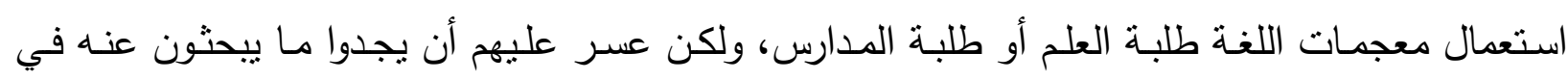
المعجمات القديمة، فكثرت الثكاوى وتلاحقت، وزاد هذه الثكاوى حدة حتى طالب بعضهـا أو كثير منها بالقضـاء على العربية الفصحى اطلاع الباحثين على معجمات اللغات الغربية التي تمتاز باليسر وتوفير الوقت فتحاول أوّل ما تحاول أن تنرح للك طلبتك وتمهد للك سبيل العثور عليها في أسرع مدة، فما الأمور التي تبعث على الثكوى في هذه المعجمات ؟ أنسات 1 - لعل أول ما يؤخذ على معجماتتا جميعاً ( التصحيف ) وقد ذكرناه في حديثنا عن كتاب العين، فالكتابة

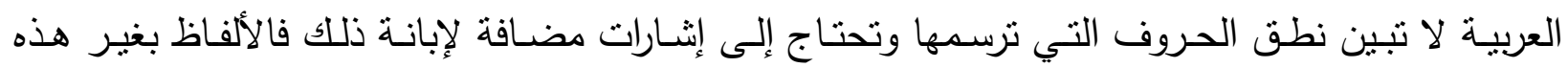
الإثـارات من الممكن أن تقرأ على عدة أوجـه، ومن الممكن ألا تقع هذه الإشـارات المضـافة في موقعها

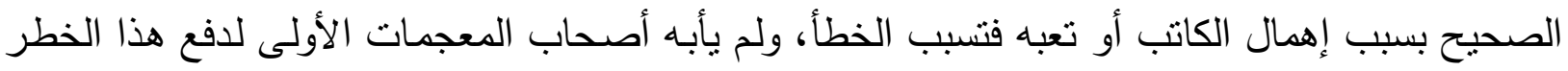

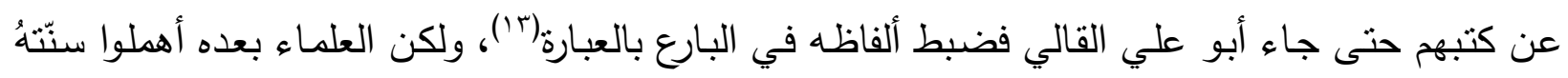

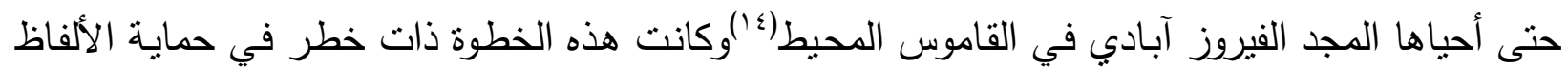

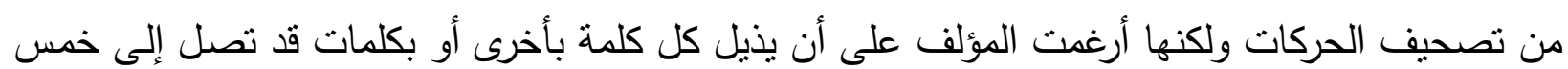

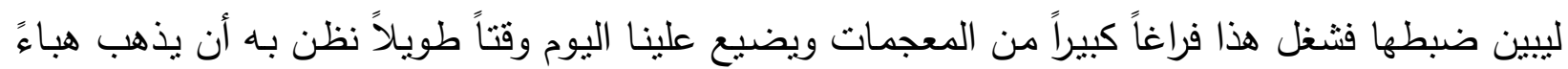
ولا حلّ لهذه المشكلة في المعجمات إلا حين تحل المشكلة برمتها في اللغة كلها وقد حاول كثير من الباحثين

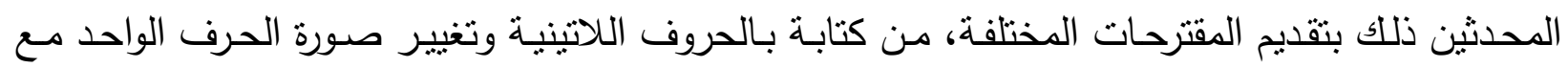

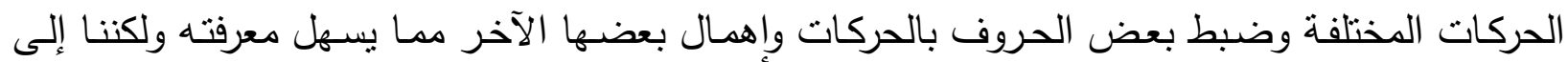

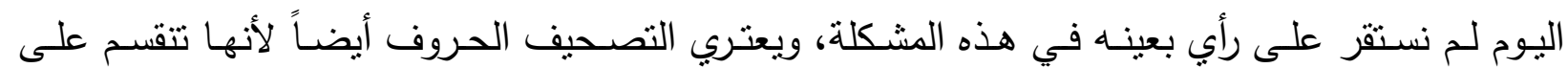

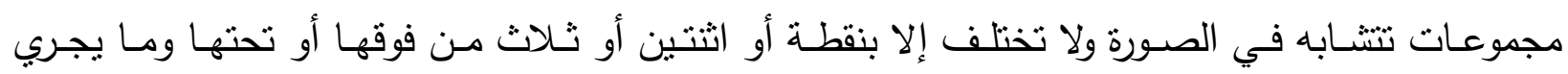

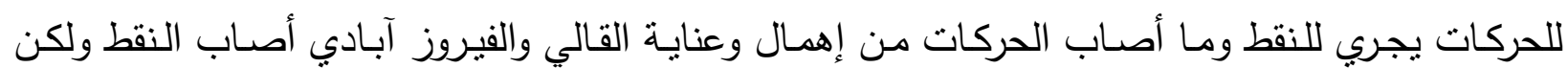
المشكلة ما زالت باقية تنتظر الحل بطرفيها، ويكفي دليلاً على خطر التصحيف انه لم يسلم منه لغوي وكما التها

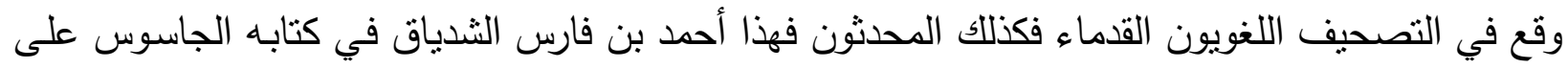

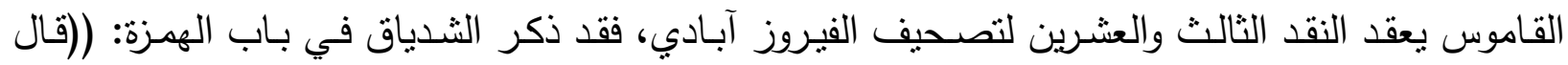

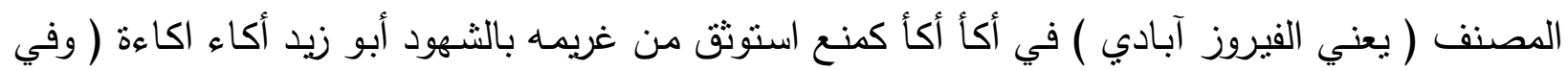

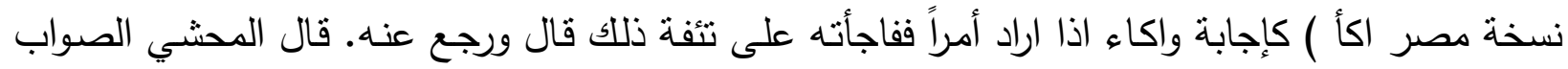


في اكاء أن يذكره في فصل الكاف كما فعل الجوهري لأن الهمزة الأولى زائدة للتعدية والنقل وكهمزة أقام

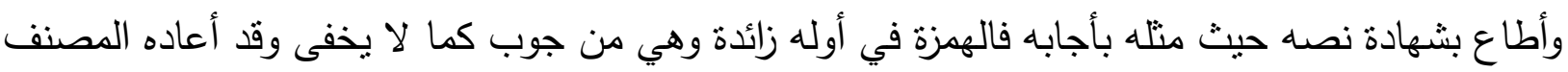

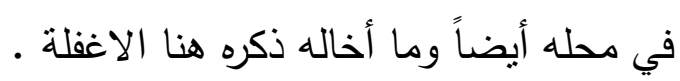
قلت لم أجد اكآهه في الصحاح وإنما ذكر كئت عن الأمر ( وفي نسخةٍ مُصرٌ على الأمر ) اذا هبته

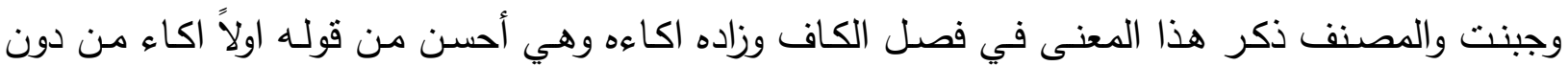

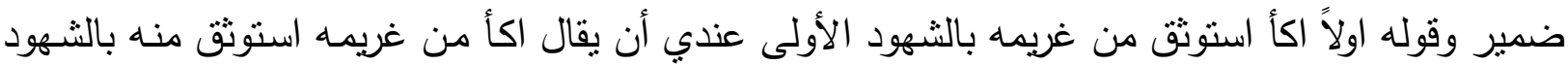

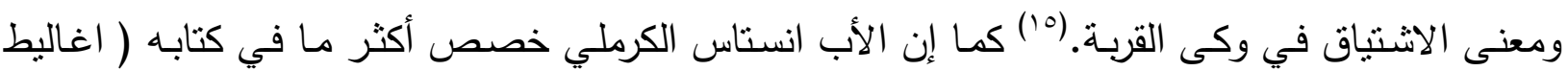
اللغويين ) لتصحيف مدرسة اليسوعيين من المعجميين، ومن آثار هذا التصحيف الواسع النطاق وجود عدد التئي كبير من الكلمات لا تعرف حركاتها ولا حروفها على وجه التعيين وكثرة الألفاظ التي ادعى فيها إبدال الحروف، ونسب ذلك إلى قبائل العرب، وابتكرت ألفاظ ربما لم تعرفها العربية ابداً، ولعل الأمر الوحيد الذي

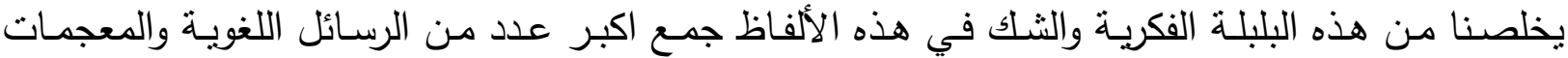
القديمة والاطلاع على ما قالته بصددها، وما تنقى منها ولم نسنطع الحكم عليه من هذه السبيل حاكمناه في ضوء الاثتنقاق، فإذا وجدنا له مادة تثترك معه في معانيه حكمنا بصحته، فإن لم نجد رجحنا تصحيحه فان

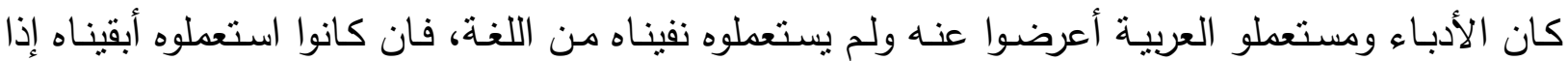

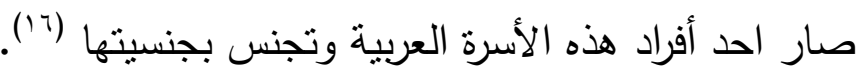
r -إن اكبر عقبة تصادف الباحث في معجماتتا اللغوية عدم ترتيب المواد نرتيباً داخلياً، فقيها خلط الأسماء

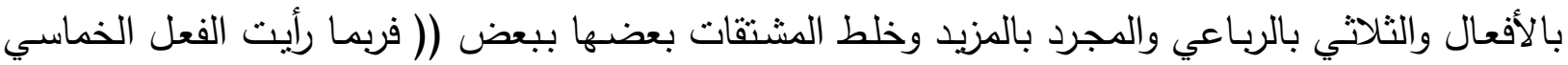

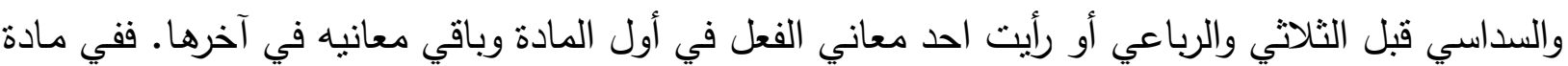
( عرض ) ذكر الجوهري المعارضة التي بمعنى المقابلة بعد المعارضة التي بمعنى المجانبة بثلاثة وثثلاثين

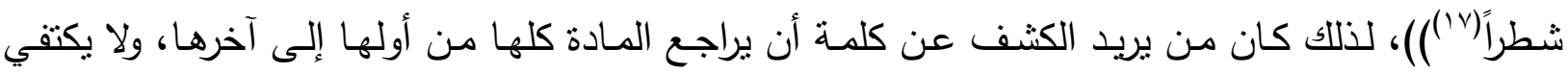
بمصادفتها في مكان واحد، فربما تكرر ذكرها . r- ويواجه الباحث في المعجمات العربية عدم التزامها المنهج الذي اختطه المؤلف لنفسه ، ومن ون أمنلة ذلك

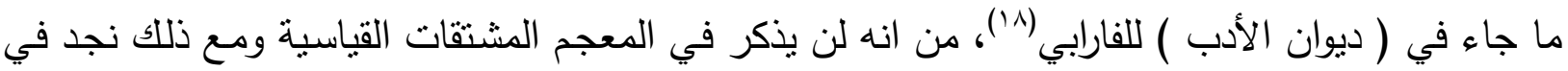

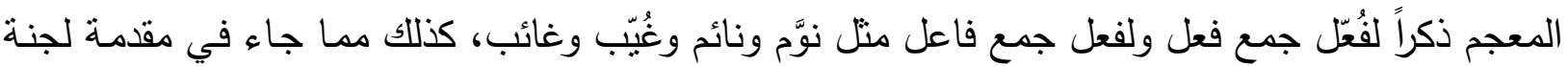

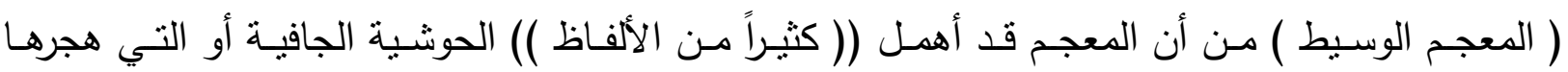

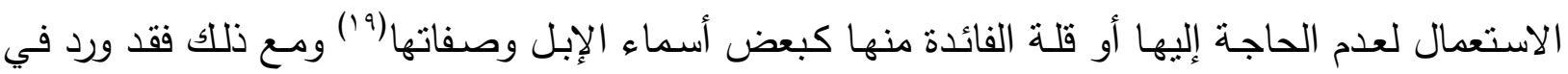
المعجم كلمات مثل الهصاهص بمعنى القوي من الناس أو الأسود ومنل الهلواع الناقة السريعة الثديدة ومثل الإنل

الناقة الدرصاء تكسرت أسنانها كبراً، ومثل الدرفاس بمعنى الضخم العظيم من الإنسان والحيوان (·r). צ- ومن عيوب المعجمات اختلافها في عدد الحروف الهجائية وترتيبها، فعند بعضهم ومن جملتهم الخليل

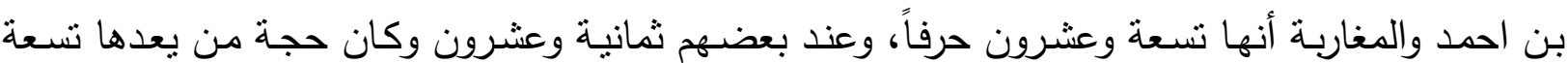


وعشرين إن الألف إحدى حروف العلة، فهي إذاً حرف، وحجة من بعدها ثمانية وعشرين أنها ( أب الألف )

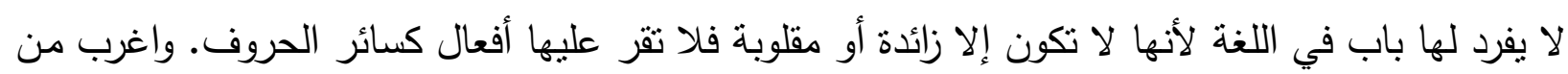

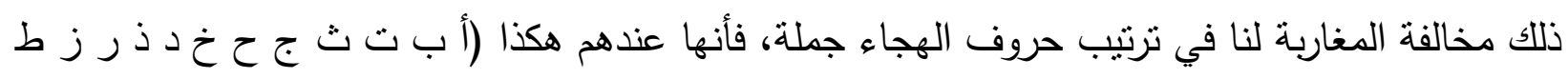

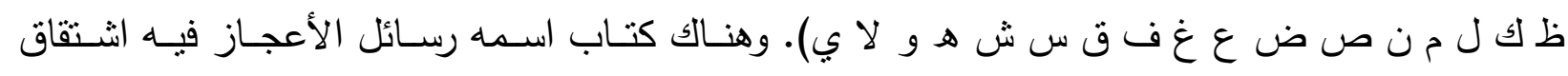

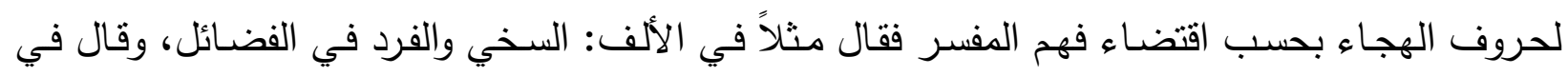

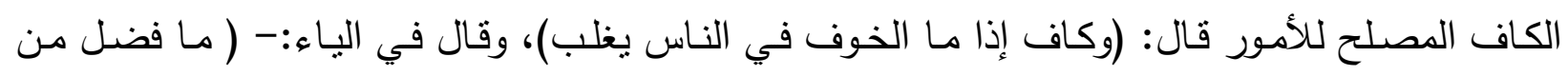

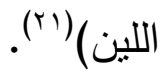
ه- ومن عيوب المعجمات أنهم يبتدئون المادة باسم الفاعل أو المفعول أو الصفة المشبهة أو اسم المكان

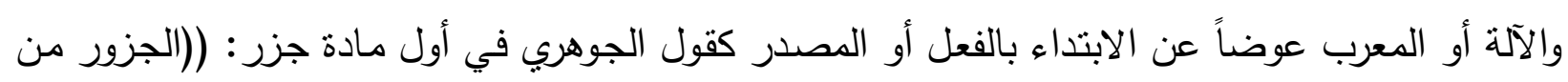

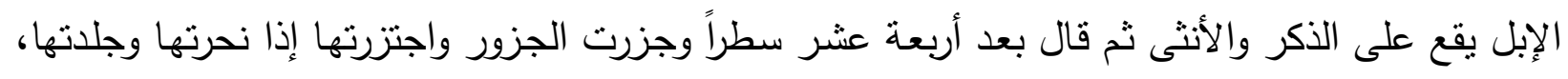

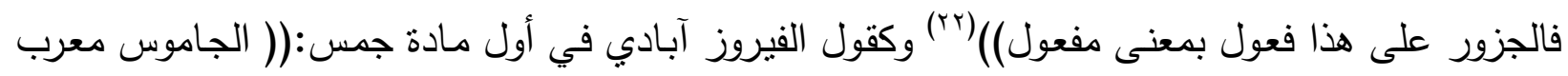

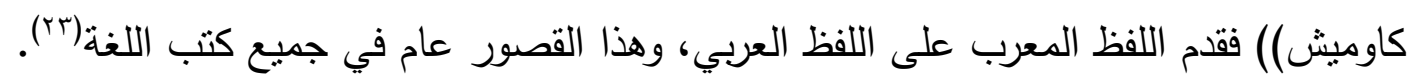

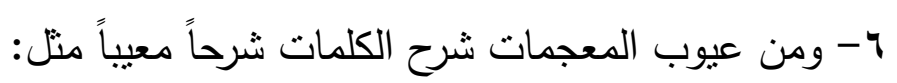

أ- غموض العبارة وتعريف اللفظ الغـامض بلفظ غـامض كقول الفارابي: (( الصدـع الوعل بين الوعلين

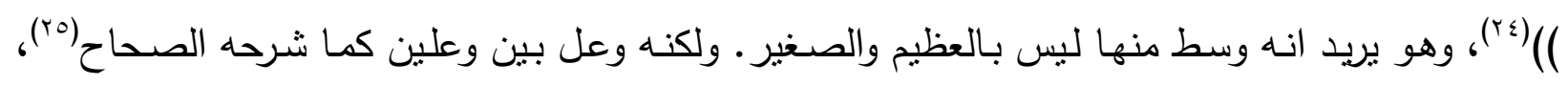

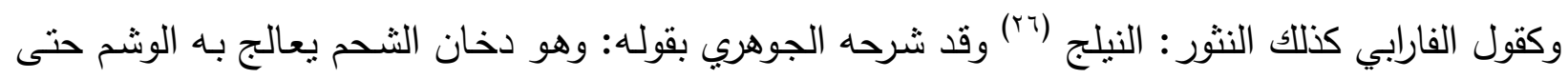
يخضر (rV) ب- عدم الدقة في التعبير كقول الفارابي: الأكلف لون بين السواد والحمرة والحقيقة أن الكلفة هي ذلك اللون،

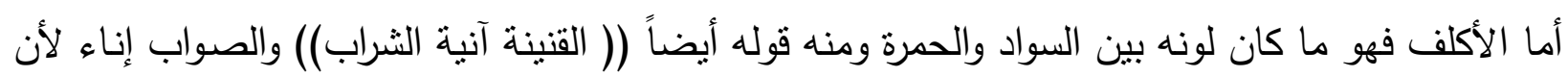

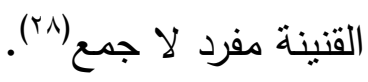

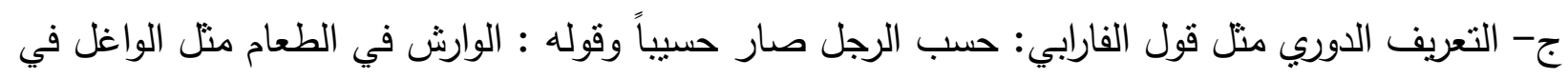

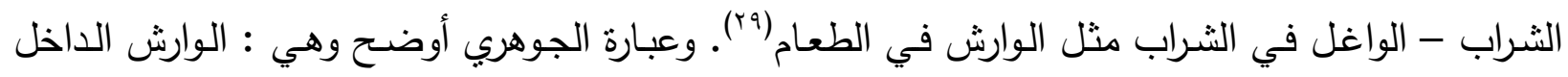

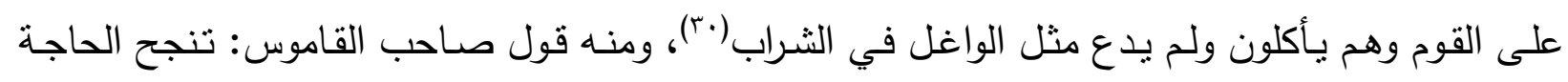

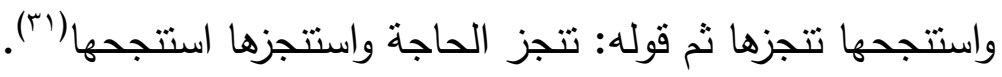

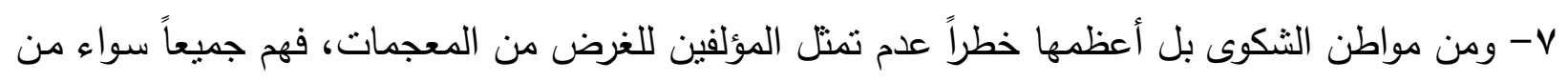

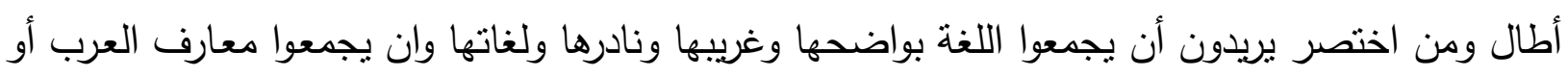

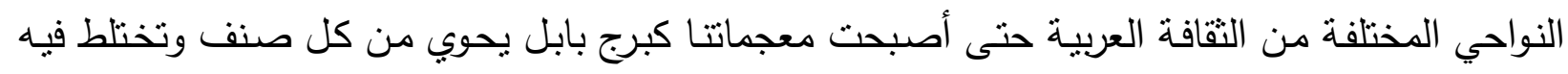

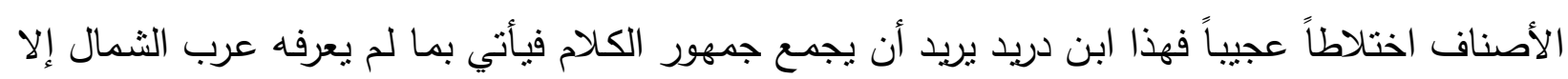

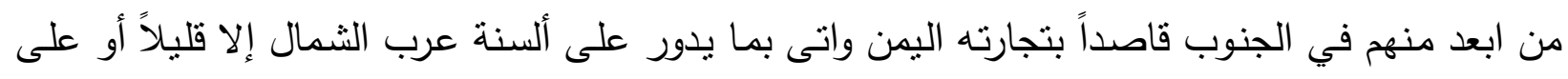
السنة قبائل متفرقة منهم فكان من النوادر وهذا ابن فارس يؤلف المجمل فيحشوه بما يزخر بهـ كتابه الأكبر 
المقاييس ويملأه بما أتى به الخليل الذي قصد ( إلى الواضح الغريب ) في معجمه وبما أنى به ابن دريد وما

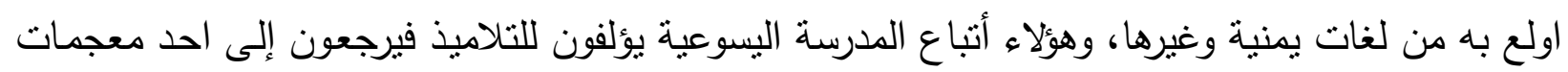

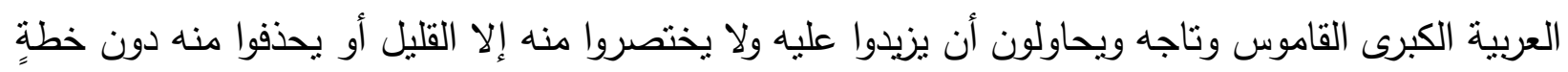

معينة.

أمـا من أطـالوا فحشـوا كتبهم بـالأعلام العربيـة والأعجميـة وأسـماء الأمـاكن والقصص والخرافـات والمفردات الطبية والاصطلاحات الغريبة حتى مصطلحات ضرب الرمل والأمور الأجنبية من الإسرائيليات والروميات والهنديات والمشتقات القياسية وما يمكن الاستغناء عنه، ودفع حب الغريب بعضهم إلى تأويل

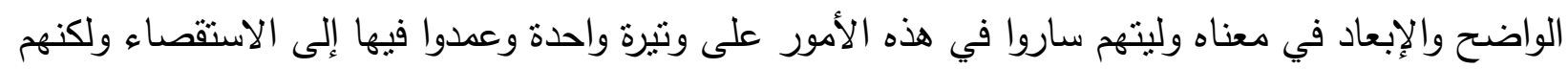

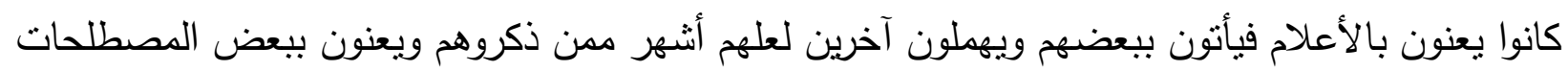

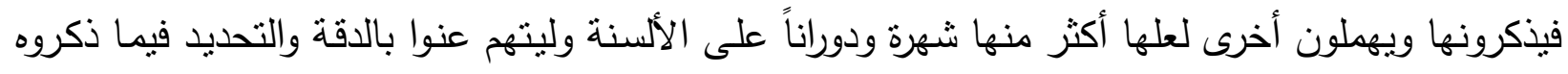

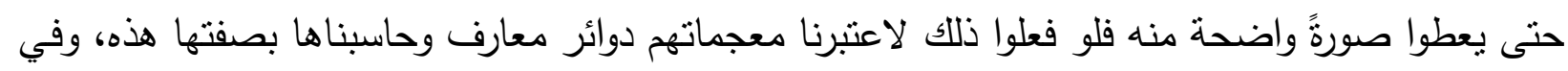

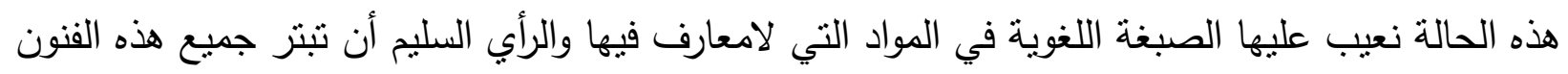
من المعجمات ولا نبقى منها إلا الألقاب التي لها دلالة خاصة والمصطلحات التهات التي كثر دورانها على الألسنة

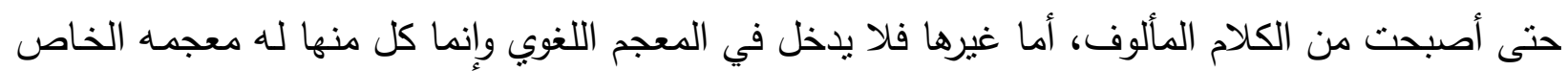

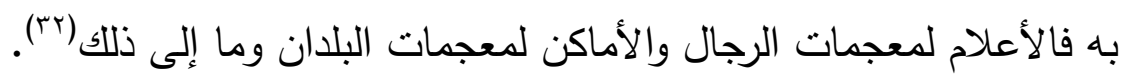

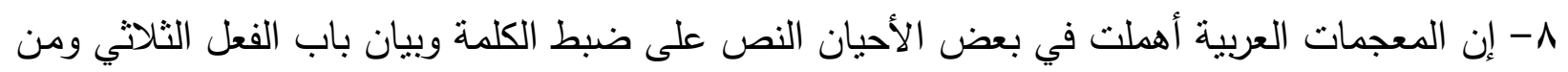
أمتلة ذلك قول الجوهري :- قلبته أي أحبت قلبه وقلبت النخلة أي نزعت قلبهان البهان ولم يذكر الباب وقد ذكر غيره

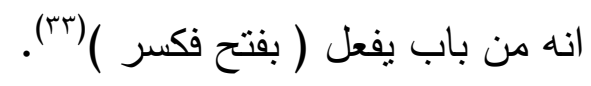
9 - من ينتبع معجمات المتأخرين يجدها تعتمد إلى حد كبير على معجمات المتقدمين، سواء أكان من ناحية

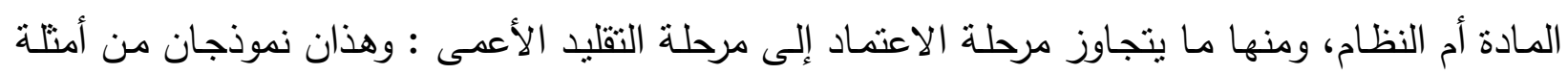

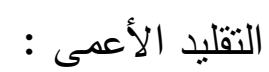

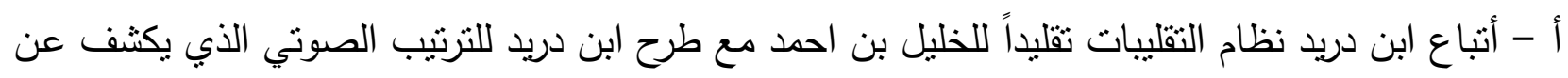
خصائص (( النسج الصوتي )) للكلمات العربية، ويميز التجمعات المسموحة والأخرى الممنوعة.

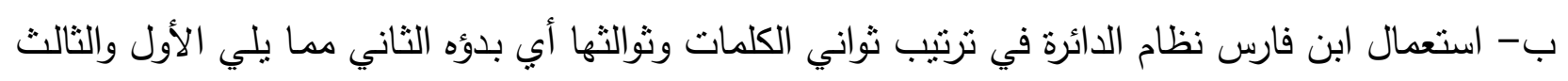

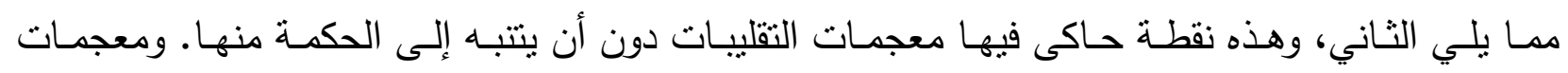

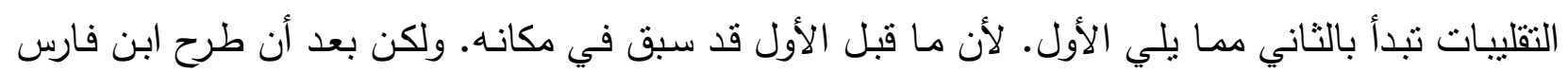

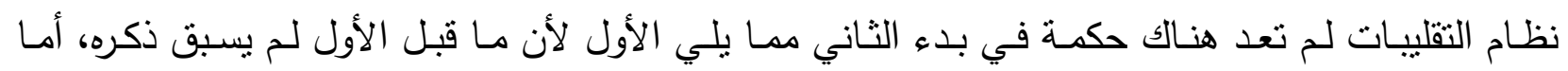

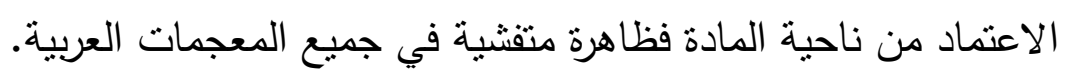

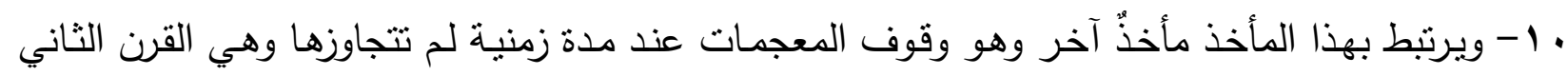

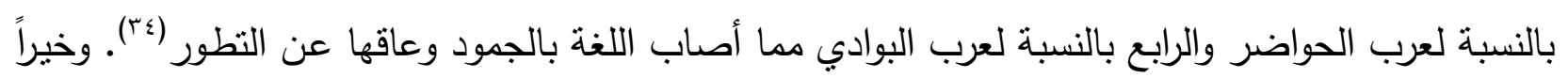


فعل واضعو المعجم الوسيط حين لم يعترفوا بانقطاع سلامة اللغة العربية عند عصر معين ولا مكان معين،

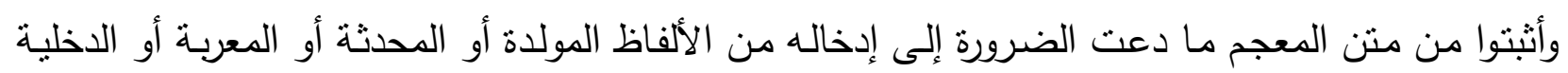

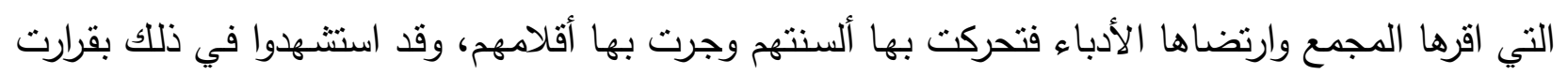

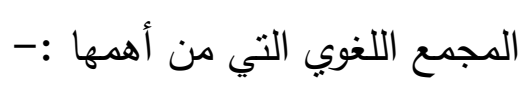
أ- فتح باب الوضع للمحدثين بوسائله المعروفة من اشتقاق وتجوز وارتجال. ب-إطلاقه القياس ليشمل ما قيس من قبل وما لم يقس.

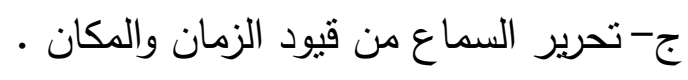

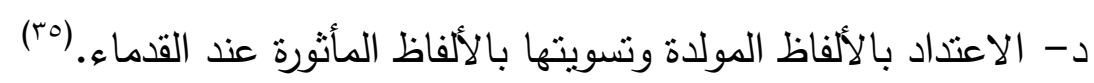

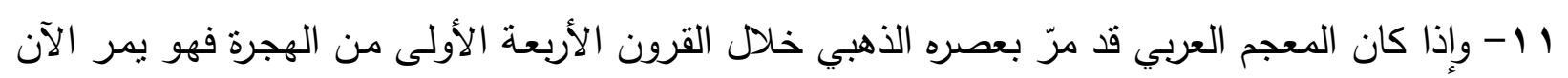

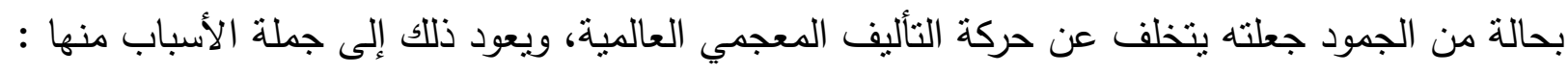

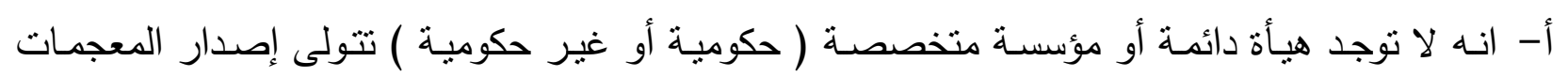

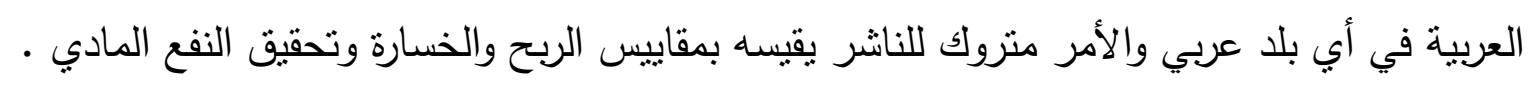

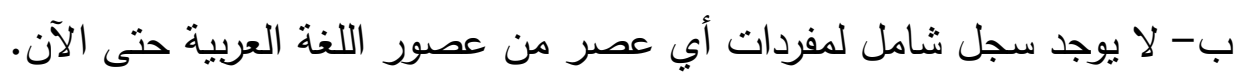

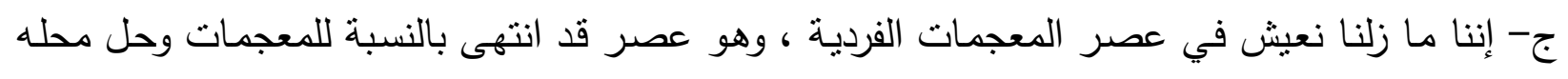

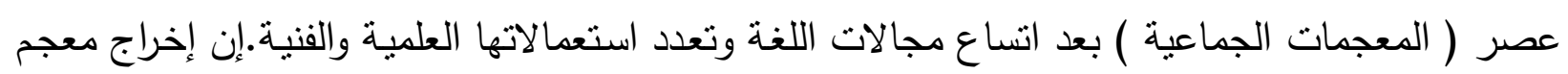

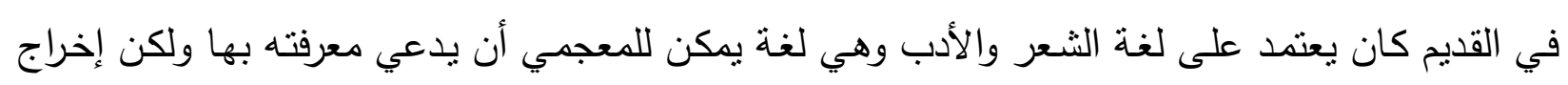

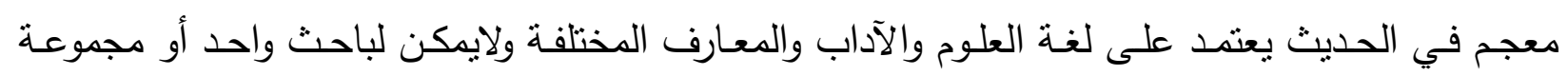

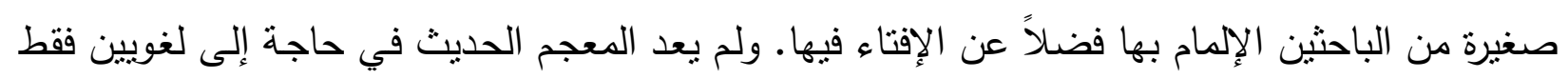

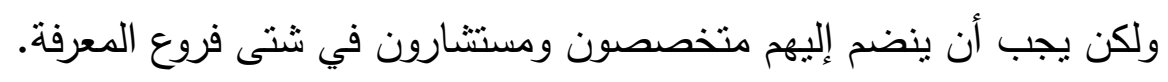

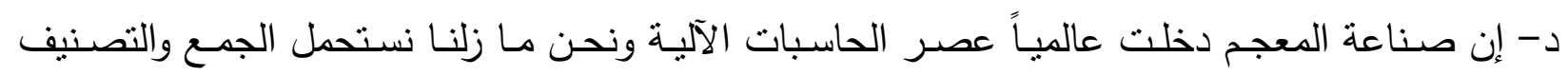

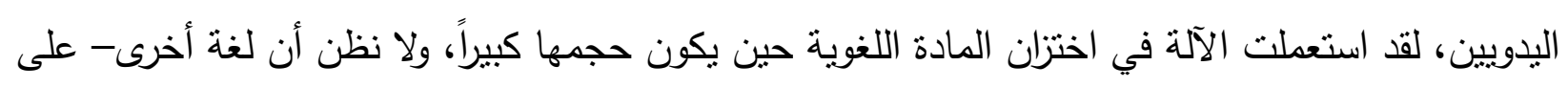

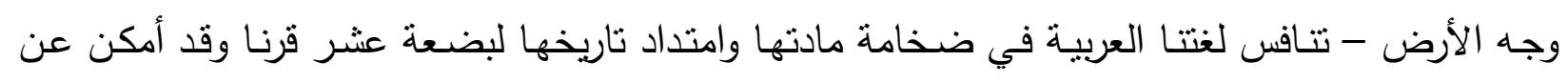
طريق الآلة حصر المادة بكل دقة والتصرف في ترتيبها بطرق مختلفة وضبط الحالات، والقيام بالتصنيفات النحوية والصرفية المختلفة وغيرها. هـ والى جانب هذِِ المشكلات فقد تطورت صناعة المعجم عالمياً من حيث الترتيب واختيار المداخل وكيفية

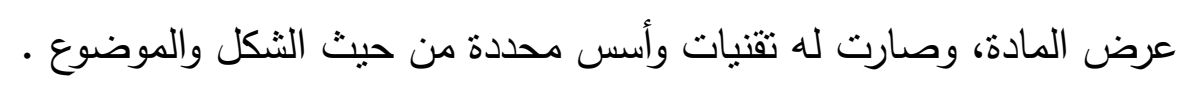

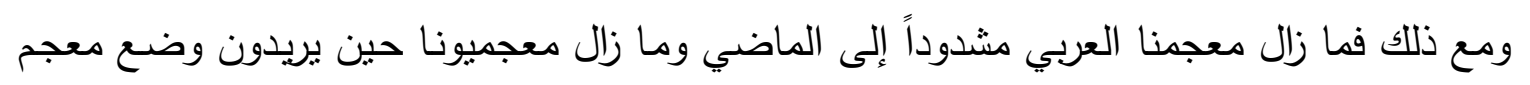

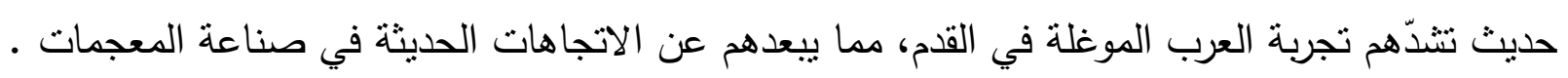

\section{$\underline{\text { Abstract }}$}

As they had said that a suitable word is a charity, we picked out such an idea of what we are discussing, hereto; to spot light on the shadow of Arabic dictionary. So, we are going to present an important task from the Language side. Whereas, they might say "May speech more than a 
battle ". Islam reinforces the concept of speech aspect. Even though the miracle of The Massager Mohammad (PBH.) ; "The Holly Qur'a" the speech Of AL-Mighty Allah , challenges human beings and Jiins to get like the Holly Qur'a ,nevertheless; either by a word from like, definitely they could not . Besides while such miracles of the previous massagers of Allah were touchable and not be mortal.

While we are going on most of time speaking, hearing, reading, and writing .So it not strange to arise among Arabs, since early centuries, scientists specialized in studying Language and collecting it's constituents placing rules, classifying sounds and for the sake of saving language itself safely making it's ability to follow up science of Arts nevertheless, standing on the absent vocabularies checking constituents of language correctly. The influential aspect of dictionary had a good affect in collecting much of vocabularies with their interpretations.

Most of studying dealt with Arabic dictionaries was little. And less than of it that dealt with certain critically to spot light on the stages of developments and recognition it's counterparts with a negative sides.

This present study is so moderate with a critical opinions on the Arabic dictionary .So, I mentioned hereto, the definition of the constituent dictionary That book which included constituents of constituents of a language in a certain theme out of it's subjects or in all types or any term whether in one or in any subject with certain arranges besides interpretations and explanations comments to state hints or references and the manner of articulation, with explanation instants. throughout this study we'll remark of the term Dictionary which is firstly named and published by old men and talker of Traditions. It was mentioned that the first book named with such a title for the first time was entitled (Attendants' Dictionary) related to Abu Ya'ala Ahmed bin Ali ; The talker of the Arabian peninsula D. 307 he. What is above is meant by the constituent ( Dictionary) is known by the scientists of The Third Century Hijri -: Book contains names out of them famous ones with definitions chronologically. There is no such a dictionary in a language like this except ( Measurement of Language Dictionary ) related Ahmed Bin Faris D.392hj. ,that means a dictionary within Language studying to mean saving language towards purify it .

This study goes to (Kitab Al-Ieen) by AL-Khalil Bin Ahmed D.175 hj., who found out the concept of linguistic Dictionary, he pointed to restricting language after he had been thought for a long time for a new genre.

It is naturally, it is not out of defects neither arguments nor lacks, but it disappear to those whose were occupied with such a new neonate Since (Kitab Al-Ieen) is the first Arabic dictionary. It might be defective and weak to in addition to it was wholly published after the death of it's author, so his successors went on writing it, out of such defects are as follows :

1. Proofreading by other researchers.

2. Grammatical and derivational defects like mention extra letter in origin term or third type term within a fourth one

3. Diversity and disagreement a copy with the other tradition

4. Neglecting used basis in language, not mentioned, since he didn't hear it.

The research is an attempt to find out defects of the dictionary, perhaps, there is proofreading in most of dictionaries, whatever we may know about proofreading till there are many words without any trip thong exactly. So many constituents that I am hereto claimed to replace or to substitute letters and according to saying of Arabs. One thing that could save us 
from such intellectual whirl is to collect many of ancient linguistic theses and dictionaries and discuss. What is remain we could not judge, from this we judged according to the derivation and what is shared with meaning we considered it if not we didn't find we correct.

The second debit is what the researcher facing in Arabic dictionary is no inner arrangement of terms, there is mixture of names with verbs, the third type with fourth type of verbs, base with derivation and so on ;therefore the researcher was strongly recommended to check the wholly item entirely, may get repetition again in somewhere.

In Arabic dictionary also facing no commitment of curriculum which had painted by the author for himself. As we got in (Divan of Art) by AL-Faraby in which he didn't mention regular derivations in the dictionary, however, we could find a hint to (Fia'al ;plural of, $F i$ 'el) in the dictionary, and ( Fi'el, plural of ,Fa'il) and other. In addition to explanations leads to ambiguity of terms.

One of the defects of the dictionaries is not represented to the purpose of the dictionary. They all in the straight path whether they increase or the length or precise; aiming to show clearance, absence and exception in a language. The golden era of the Arabic dictionary was through the early four centuries from Hijra, so, it had gotten starvation leads to be back from the Historical publish Movement in the glob all these related to the following accuses :

1. There is certain commission specialized (Government or non-government) regarded to publish and issue the Arabic dictionaries.

2. We have still live in era with dictionary of single effort. So the modern dictionary in need of specialists in several branch of knowledge.

3. Making dictionaries could make use of computer systems and programs, and we still used of handle classification like the previous Arabic experiences.

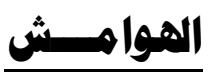

ا. ينظر ناريخ العربية / د. عبد الحسين الفتلي د. رشيد العبيدي د. طارق الجنابي مؤسسة دار الكتب للطباعة والنشر.

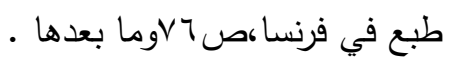

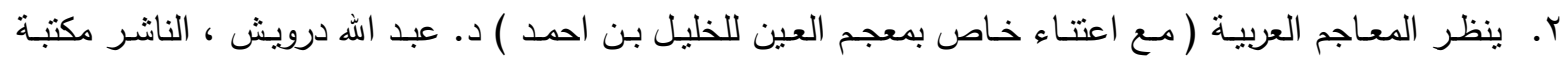

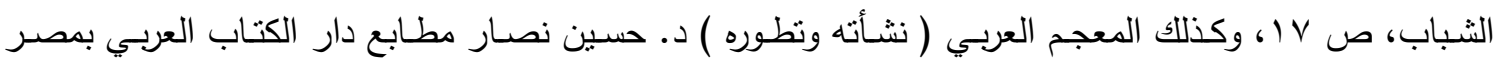

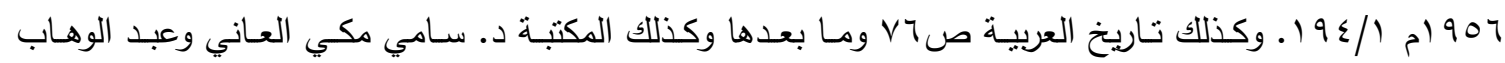

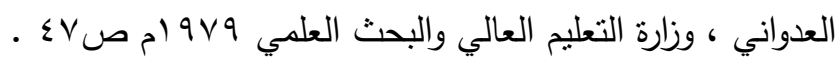

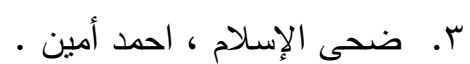

ع. ـ المزهر في علوم اللغـة وأنواعها،عبد الرحمن جـلال الدين السيوطي، تحقيق محمد احمد جاد المولى ومحمد أبو

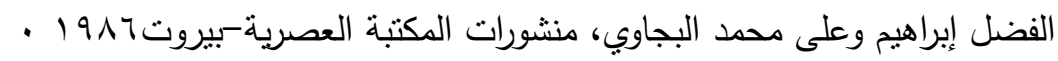

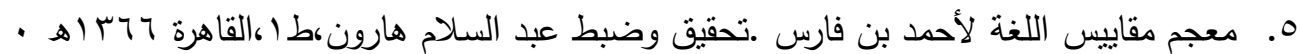

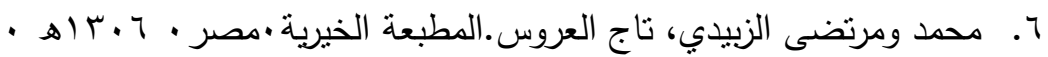

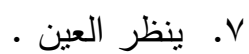

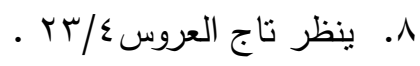

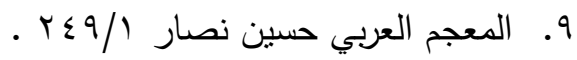

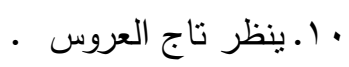




$$
\begin{aligned}
& \text { 11 ـ ينظر العين ( بعض الأبنية التي كانت عند الخليل مهملة ) . }
\end{aligned}
$$

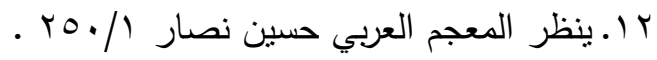

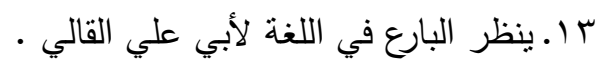

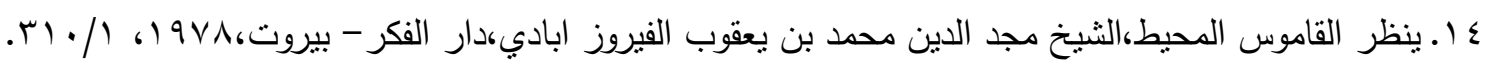
ا ـ ينظر القاموس المحيط وينظر الجاسوس على القاموس . احمد فارس الثدياق قسطنطينية طبع في مطبعة الجوائب

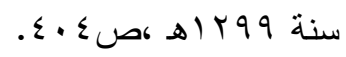

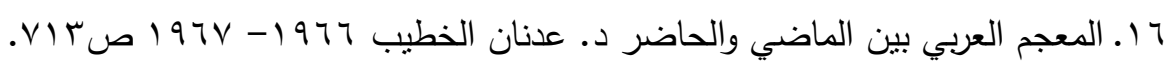

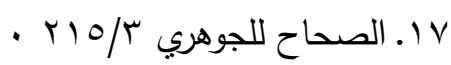
1 ا. ينظر ديوان الأدب للفارابي (مواد مختلفة).

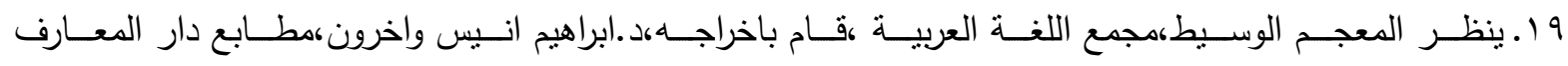

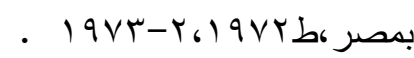

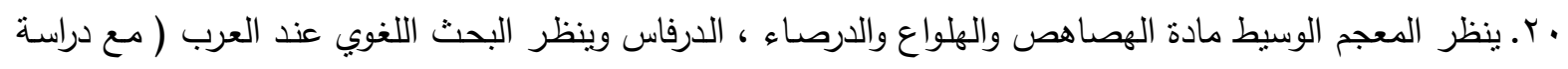

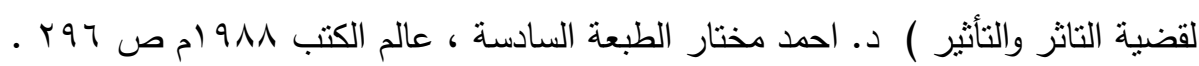
اب. ينظر الجاسوس على القاموس ص اء

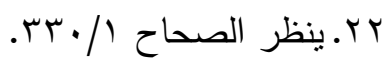

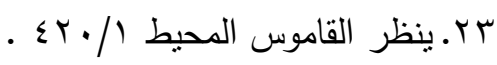
ع ع. ينظر ديوان الأدب للفارابي

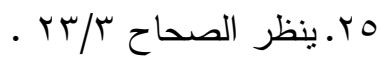

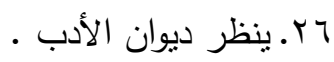

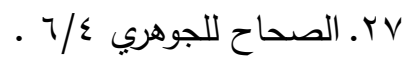

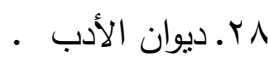

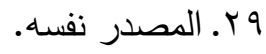

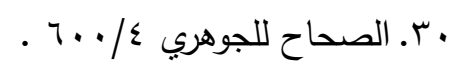

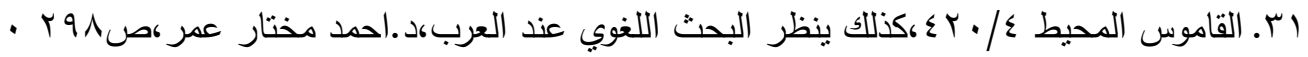

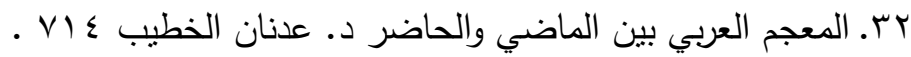

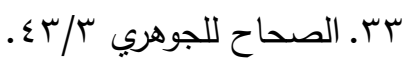

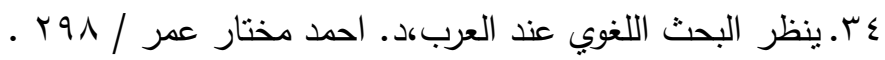

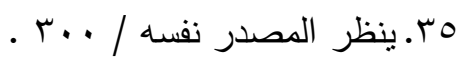




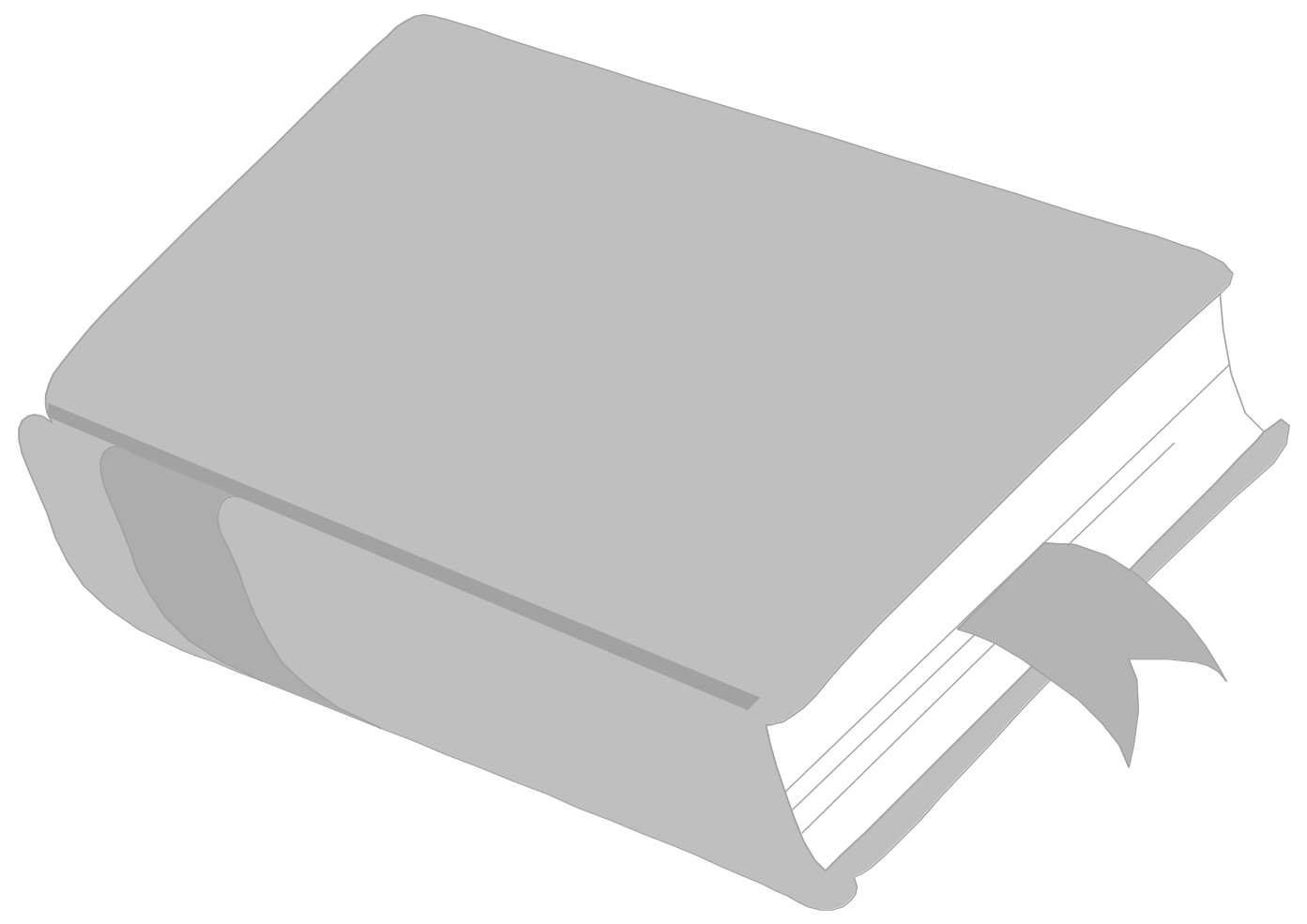

$\Lambda \varepsilon$ 